\title{
SEASONAL CHANGES OF WETNESS CONDITIONS IN THE ŁASICA CATCHMENT (POLAND)
}

\section{INTRODUCTION}

The soil moisture represents an important variable on which a question is often addressed in many water management problems. The water storage in the upper soil layers is of great importance for sustaining and restoring natural forests, wetlands or meadows ecosystems. Soil moisture content considered as hydrologic variable represents water retention in top soil layers. The importace of this variable is that it can limit or enhance species richeness throughout water availability. Especially for wetlands and forests, water conditions constituate a basis for its functioning.

The undertaken ${ }^{*}$ study has been carried out in order to estimate current wetness conditions in the Łasica catchment, Poland. Its considerable part is situated within the boundaries of the Kampinos National Park. This fact implies enhanced needs of environmental policies for protection and integrated management of remaining quasi-natural environments. In this context water management, including management of water resources in the upper soil layers, should meet requirements imposed by different ecosystems.

Soil moisture measurements have been conducted by the Time-DomainReflectometry (TDR) meter in Spring, Summer and Fall seasons of 1995, 1996 and 1997. Collected soil moisture data have been used to determine water storage in the upper $0-10 \mathrm{~cm}, 0-50 \mathrm{~cm}$ and $0-100 \mathrm{~cm}$ soil layers, both for each selected measurement site and for the entire catchment on average.

Undertaken research provides valuable information on the current wetness conditions and their variability within hydrologic year. The obtained values of water storage have been checked for their interdependancies;

\footnotetext{
* The author wishes to thank the Department of Environmental Sciences and Policy of the Central European University that has supported this research by a grant No.92-14. This has allowed seasonal field measurements of soil moisture with TDR meter purchased for this studies.
} 
relations between the water storage in the $0-10 \mathrm{~cm}, 0-50 \mathrm{~cm}$ and $0-100 \mathrm{~cm}$ layers have been established for the entire catchment.

Field measurements taken by TDR method are conducted within the Easica catchment for the first time. Results are of great importace in detecting available catchment water resources in the top soil layers. This research supports current efforts to control and manage water resources in the region. The continuing collection of data and investigations are still required for further developments.

\section{THE IMPORTANCE OF THE SOIL MOISTURE ESTIMATES}

Estimates of soil moisture content in the root zone or in the top metre is important for many hydrologic applications. Frequently, estimates of soil moisture content are incorporated in a comprehensive catchment models that can be used as analytical tool for planning and management of water resources. The hydrologic models use parameters to represent catchment as a whole, whereas data on catchment characteristics are collected at a number of field locations. Thus point measurements should represent different soil conditions due to its spatial variability.

Hydrological processes within a catchment are very complex due to their dynamics and heterogeneity. Flow generation processes are highly dependent on the wetness conditions in a catchment. It is impossible to incororate all detected heterogeneity of catchment physical characteristics in a relatively simple, single parameters. However in order to attempt to capture these complex processes, the need for single, collective measure exists. In practice catchment wetness conditions can be approached by the single index which represents the weighted mean value of water stored in the catchment soil mantle.

There are several recent field studies reported in the literature in which TDR technique or other traditional methods are used to determine the volumetric soil moisture content in the field (Goyal et all, 1996; Nyberg, 1996; Ragab, 1995; Vissers, Sanden, 1993). Such field studies are still of great importance in order to provide reliable and direct estimates of the soil moisture content from which catchment wetness conditions can be derived.

\section{GENERAL CHARACTERISTICS OF THE STUDY REGION}

The area chosen for studies is Łasica catchment of approximately 500 sq.km. It is situated in the central region of Poland, on the Mazovian Lowland. The most important characteristics of the study region are the following:

1. The elevations in the catchment are within the range $65-110 \mathrm{~m}$ above see level. Contrasts in elevations are due to appearance of flat areas separated by the zones of dunes forming latitude series. 
2. In the past this was a wild area famous for its natural wetlands. Characteristically distinct features of the nature of the Kampinos Wood are complexes of inland wooded dunes and parallel peat bogs.

3. Original hydrographic structure has been changed considerable by the creation of artificial drainage systems stimulating outflow from naturally flat areas identified with wetlands. Drainage system was designed in order to intensify agricultural production before the area gained protection status. It has caused the process of wetland drainage and changes in land use from natural character towards arable fields and grassland.

4. Most of the area is covered by podsol and peaty soils and only the south part of the catchment is formed by brown soils. General direction of shallow groundwater flows coincides with the surface slopes.

5. The region requires special attention. Determination of optimal conditions for existing and renaturized ecosystems is required.

\section{FIELD MEASUREMENTS OF THE SOIL MOISTURE}

The soil water content in a particular soil layer is dependent on several factors. However the main sinks for soil water are percolation to the saturated zone during the winter season and evapotranspiration during the summer season (Nyberg, 1996).

In order to estimate wetness conditions in the entire catchment, representative measurements sites have been chosen based on the hydrogeologic features of the Easica catchment (Kazimierski, 1996). The chosen sites are situated within two types of distinquished zones of different regimes. Wet zones that appeare within flat areas are characterized by relatively shallow groundwater table, hydromorphic soils and insignificant influence of precipitation on the groundwater table. As the groundwater table in the recent 30 years has been decreased in the entire catchment, these conditions in wet zones are often disturbed. Within dry zones the groundwater table is found at greater depths. In these zones the infiltration is the main source for soil water content.

Conventional laboratory procedures for water content measurements are often slow and time consuming. Alternative solution for soil moisture measurements is an application of moisture meter working with the method of Time-Domain-Reflectometry. The TDR method has become a standard that is applied in a number of field equipment offered by, among others, TRIMESystem, TRASE System or EASY TEST. This techniques realizes a quasi-simultaneous measurements being taken directly in the field. It requires no preparation of the soil sample, no drying with long waiting period and no errors by taking the samples. Principle of the TDR is that there is a unique relation between the volumetric water content and the dielectric constant for soils.

Field Operated Meter (FOM) produced by Easy Test, Poland (1995) was 
used for determination of soil moistures in the field. FOM is a TDR technology based, portable, battery operated, microprocessor controlled device designed for in situ field measurements of soil moisture, temperature and salinity from the same probe. It is designated for periodic measurements at random or fixed location where these characteristics are to be determinated by readings taken at various levels of the soil profile. It utilizes the FP/mtstype probes.

Field measurements have been conducted at three transects (Fig. 1). Chosen measurement sites are located within wet and dry zones and represents two main types of hydrogeologic regime (Kazimierski, 1996).

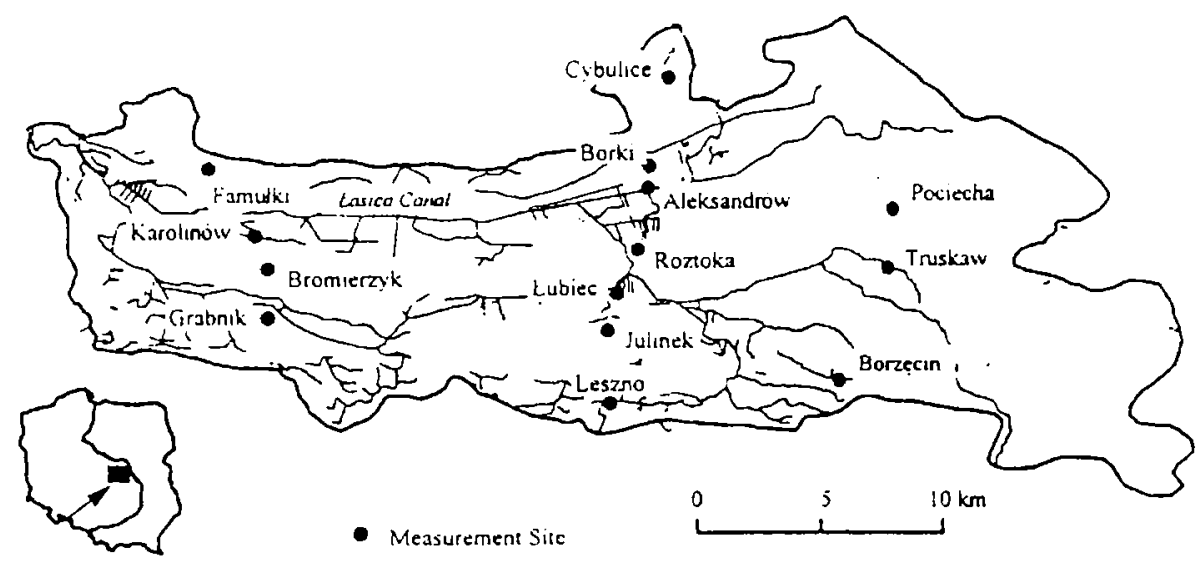

Fig. 1. Location of measurement sites in the Łasica catchment, Poland.

Soil moisture measurements have been conducted at different depths reaching the first found saturated layer. Soil drillings are of different depth, from $50 \mathrm{~cm}$ in case of lowland locations, to $200 \mathrm{~cm}$ in case of deeper appearance of saturated layers. In the further considerations sites with shallow groundwater table are considered as "wet sites", the others - as "dry sites".

\section{CATCHMENT WETNESS CONDITIONS - RESULTS AND DISCUSSION}

From the soil moisture data, water storage for the $0-10 \mathrm{~cm}, 0-50 \mathrm{~cm}$ and 0-100 cm layers has been derived for each measurement site and for the entire catchment on average. Changes in time of catchment water storage during observation period of 24-months have been shown at Fig. 2 and Table 1.

Analysing the seasonal variability of water storage in the considered top soil layers, the following general tendencies have been observed:

1. After winter season, in spring, water content is often found at maximum level. 
Changes of Water Storage in the Soil Layer of $1 \mathrm{~m}$ depth for the entire

\begin{tabular}{|l|c|c|c|c|c|c|}
\hline \multirow{2}{*}{\multicolumn{1}{c|}{ Sites }} & \multicolumn{6}{c|}{ Increase (+) or decrease (-) in water storage (mm) } \\
\cline { 2 - 7 } & \multicolumn{7}{|c|}{ Period } \\
\cline { 2 - 8 } & $04.95-$ & $07.95-$ & $11.95-$ & $05.96-$ & $08.96-$ & $11.96-$ \\
& -6.95 & -10.95 & -04.96 & -07.96 & -10.96 & 04.97 \\
\hline The entire catchment & -45 & +30 & +18 & -36 & -21 & +38 \\
Wet sites & -44 & +32 & +13 & -55 & -16 & +41 \\
Dry sites & -46 & +27 & +24 & -17 & -27 & +35 \\
\hline
\end{tabular}

Average values for the entire catchment

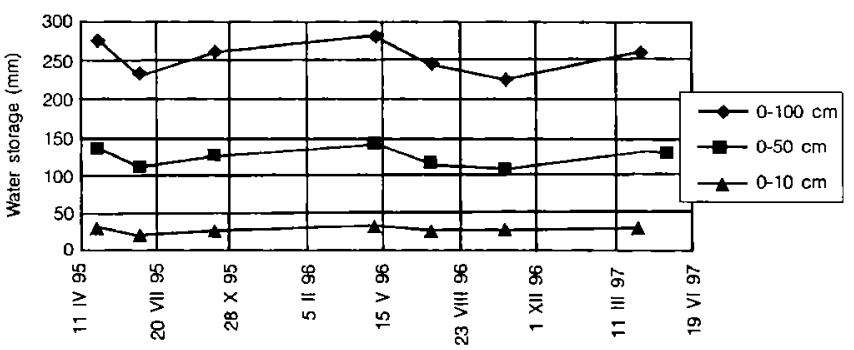

Average values for wet sites

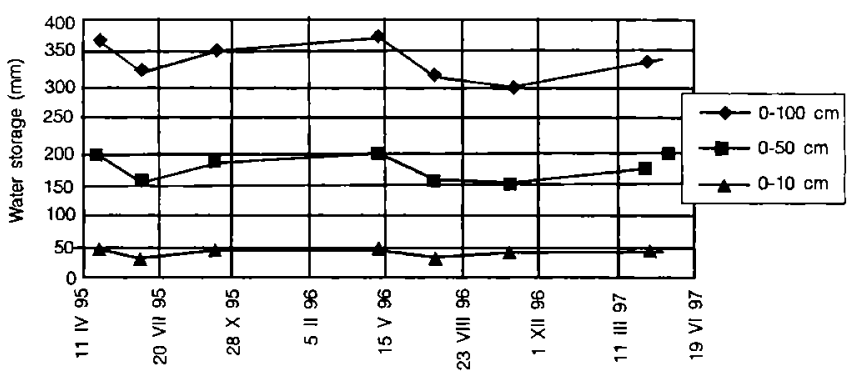

Average values for dry sites

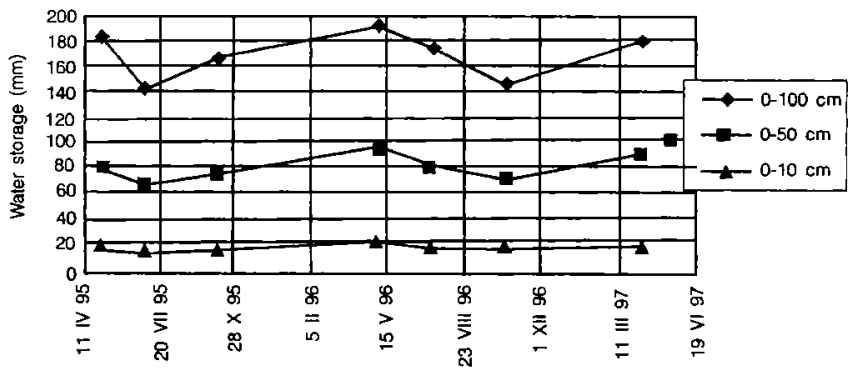

Fig. 2. Changes in Time of Water Storage in the $0-10 \mathrm{~cm}, 0-50 \mathrm{~cm}$ and $0-100 \mathrm{~cm}$ soil layers during observation period 24 months. 
2. During Spring-Summer season a considerable decrease in soil moisture content and water storage is observed that leeds to appearance of the lowest moisture content at the end of Summer and beginning of Fall seasons. After that, during late Fall and Winter, due to increase in precipitation and decrease in evapotranspiration, soil moisture content and corresponding water storage increase gradually. These tendencies are observed at all selected sites, considered separately as well as considered on average for "wet sites", "dry sites" as well as for the whole catchment on average.

Besides seasonal changes in water storage, there are differences in water storage between particular years. Comparison of the wetness conditions found in Spring 1995, 1996 and 1997 has shown considerable differences. The water storage values are presented in Table 2 . The lowest values of spring water storage have appeared in 1997. This has to be considered as a consequence of relatively low water storages that have been detected in Fall 1996. As a result, water storage in wet sites has appeared to be relatively sensible for the antecedent moisture conditions as it remains relatively low in the upper $50 \mathrm{~cm}$ and $100 \mathrm{~cm}$ layers in Spring 1997. Decrease in water storage during Spring- Summer season 1997 starts from relatively low water storage, that is $30-40 \mathrm{~mm}$ lower than storages during other two Spring seasons.

Table 2

Comparison of spring wetness conditions found in 1995, 1996 and 1997

\begin{tabular}{|l|c|c|c|c|c|c|}
\hline \multirow{2}{*}{ Water storage in: } & \multicolumn{3}{|c|}{ The entire catchment } & \multicolumn{3}{c|}{ Wet sites } \\
\cline { 2 - 7 } & $0.1 \mathrm{~m}$ & $0.5 \mathrm{~m}$ & $1.0 \mathrm{~m}$ & $0.1 \mathrm{~m}$ & $0.5 \mathrm{~m}$ & $1.0 \mathrm{~m}$ \\
\hline Spring 1995 & 31 & 136 & 278 & 46 & 192 & 370 \\
Spring 1996 & 34 & 144 & 281 & 47 & 193 & 371 \\
Spring 1997 & 30 & 130 & 261 & 43 & 171 & 340 \\
\hline
\end{tabular}

Relationships between the water storage in the upper 10,50 and $100 \mathrm{~cm}$ layers have been investigated and shown at Figure 3 . The linear regression equations have been used to evaluate interdependancies. The following relationships have been investigated:

- the relationship between $0-10 \mathrm{~cm}$ water storage and the water storage of the $0-50 \mathrm{~cm}$ layer,

- the relationship between $0-10 \mathrm{~cm}$ water storage and the water storage of the $0-100 \mathrm{~cm}$ layer, and

- the relationship between $0-50 \mathrm{~cm}$ water storage and the water storage of the $0-100 \mathrm{~cm}$ layer for the entire catchment, for the wet sites and dry sites separately.

Strong coefficient of determination was obtained in case of the relationship between $0-50 \mathrm{~cm}$ water storage and the water storage of the $0-100 \mathrm{~cm}$ layer. As the regression of these layers shows a good linear fit, the potential 
exists for using the regression equations to compute $0-100 \mathrm{~cm}$ water storage from the $0-50 \mathrm{~cm}$. However extrapolation of these relations to other situations needs careful consideration, as the number of correlated events is small.

The relationship between the water storage in the $0-10$ and $0-50 \mathrm{~cm}$ layer

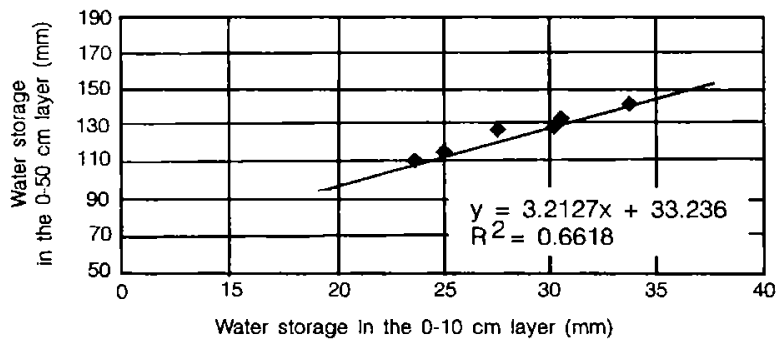

The relationship between the water storage in the $0-10$ and $0-100 \mathrm{~cm}$ layer

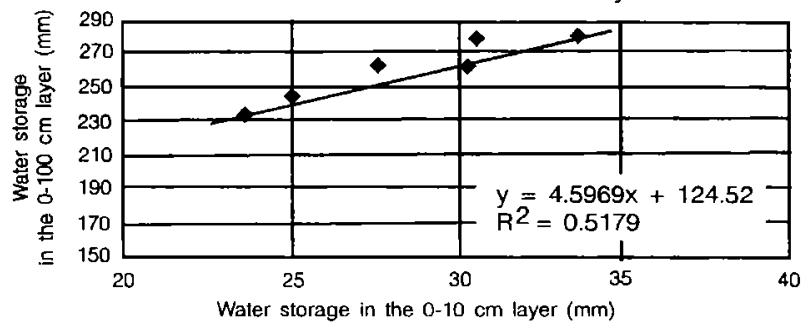

The relationship between the water storage in the $0-50$ and $0-100 \mathrm{~cm}$ layer

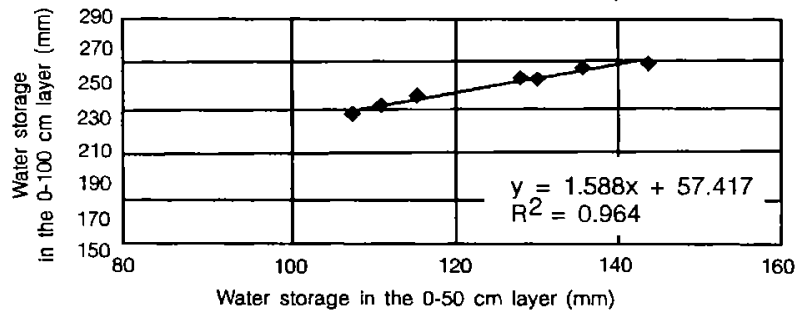

Fig. 3. The relationship between the water storage in the $0-10 \mathrm{~cm}, 0-50 \mathrm{~cm}$ and $0-100 \mathrm{~cm}$ soil layers.

The possibility of estimating water storage of the $(0-50 \mathrm{~cm})$ layer from the storage of $(0-10 \mathrm{~cm})$ in light of currently collected data is limited. Therefore further collection of data has been planned to establish a reliable relationship with reasonable coefficient of determination. 


\section{CONCLUSIONS}

The undertaken studies provide ground truth information on soil moisture content and water storage in the top soil layers within the Easica catchment. Variability range of current wetness conditions has been detected based on field measurements conducted in different seasons of hydrologic year. The obtained results represent wetness conditions found in the catchment where signifficant part of the area is covered by relatively wet and flat areas. This has direct effect in the water storage found in the upper soil mantle. Comparing these results on a catchment scale to the values obtained for other lowland catchment by Jaworski, Mynarczyk (1976), the water storage as weighted mean value is here relatively higher.

The results presented here is an attempt to extrapolate surface information on soil moisture to subsurface moisture contents. The subsurface 0 $100 \mathrm{~cm}$ water storage can be obtained from the surface $0-50 \mathrm{~cm}$ water storage layer as the dependancy has shown a good linear fit with strong coefficient of determination. The obtained interdependancies between the soil moisture of the $0-10 \mathrm{~cm}$ and the $0-50 \mathrm{~cm}$ water storage are similar to those presented by Ragab (1995), however the regression coefficients in this study have shown weaker correlation.

The research described here is a step towards identification of catchment wetness conditions on a regional level. Further collection of ground truth data of surface and subsurface moisture contents are required for the spatial distribution of soil at a regional scale.

\section{REFERENCES}

Goy a l V.C., Gupta P.K., Seth S.M., Singh V.N., 1996, Estimation of temporal changes in soil moisture using resistivity method, Hydrol.Processes, 10, 11471154.

Easy Test, 1995, Produktinformation: Easy Test Field Operating Meter for the Moisture, Temperature and Salinity of Soils, Reference Manual. Easy Test Ltd., Lublin, Poland.

Jaworski J., Młynarczyk B., 1976, Przestrzenna zmienność uwilgotnienia górnej strefy aeracji w zlewni Wilgi, Wiad. Meteorologii i Gospodarki Wodnej, III, .2.

Ka zimierski B., 1996, Stosunki wodne Kampinoskiego Parku Narodowego na tle jego struktury hydrogeologicznej, in: Ekologiczno-hydrologiczne problemy Kampinoskiego Parku Narodowego, Kampinoski Park Narodowy, Izabelin.

Nyberg L., 1996, Spatial Variability of Soil Water Content in the covered catchment at Gardsjon, Sweden, Hydrol. Processes, 10, 89-103.

$\mathrm{R}$ a g a b R., 1995, Towards a continuous operational system to estimate the root-zone soil moisture from intermittent remotely sensed surface moisture, J. Hydrol., $175,1-23$.

Viessers M.A.M., van der S anden J.J., 1993, Groundtruth Collection for the JPL-SAR and ERS-1 Campaign in Flevoland and the Veluwe (NL), 1991, Wageningen Agricultural University, Dept. of Water Resources, Den Haag. 